\title{
Suitability of human juvenile pancreatic islets for clinical use
}

\author{
A. N. Balamurugan $\cdot$ Y. Chang $\cdot$ S. Bertera $\cdot$ A. Sands $\cdot$ \\ V. Shankar $\cdot$ M. Trucco $\cdot$ R. Bottino
}

Received: 6 March 2006 / Accepted: 20 April 2006 / Published online: 17 June 2006

(C) Springer-Verlag 2006

\begin{abstract}
Aims/hypothesis The limited availability of deceased donor pancreases suitable for pancreas and islet transplantation calls for a broader utilisation of donor tissue for transplantation purposes. Young donors, representing, fortunately, a minor but significant pool of individuals, have been largely under-employed, mainly because of anatomical and functional incompatibilities with potential recipients. For islet transplantation, the isolation of pancreatic islets from young donors rarely occurs, because of technical problems. As a result of the peculiar characteristics of young donor pancreases, the standard isolation procedure does not allow efficient separation of the islets from the surrounding exocrine tissue, and favours the generation of mantled islets. Nonetheless, young donor islets offer high qualitative and clinically appealing characteristics.

Subjects and methods We standardised a modified methodology to obtain purified and mantle-free human islets from young donors. This method principally involves
\end{abstract}

\footnotetext{
A. N. Balamurugan

Thomas E. Starzl Transplantation Institute,

Department of Surgery, University of Pittsburgh,

Pittsburgh, PA, USA

A. N. Balamurugan $\cdot$ Y. Chang $\cdot$ S. Bertera $\cdot$ A. Sands $\cdot$

M. Trucco $\cdot$ R. Bottino $(\bowtie)$

Division of Immunogenetics, Department of Pediatrics,

University of Pittsburgh School of Medicine,

Children's Hospital of Pittsburgh,

Pittsburgh, PA, USA

e-mail: rib16@pitt.edu

V. Shankar

Department of Biostatistics, University of North Carolina,

Chapel Hill, NC, USA
}

efficient delivery of isolation enzyme with reduced mechanical disruption of the pancreas combined with additional filtration steps.

Results We were able to obtain purified and mantle-free human islets from donors as young as 6 months of age with good morphological and functional properties. The good qualitative characteristics of the islets, evidenced in vitro, were proven in vivo, as they were qualitatively superior to islets of older donors in transplantation studies.

Conclusions/interpretation This study justifies the utilisation of islets derived from young donors for islet transplantation.

Keywords Islet isolation · Islet transplantation - Mantled islets . Young pancreas donors

\section{Abbreviations \\ H\&E haematoxylin and eosin \\ IEQ islet equivalent number}

\section{Introduction}

New research lines focusing on the use of embryonic stem cells or xeno-transplantation, or based on the generation of insulin-producing cells from adult stem cell sources, will hopefully result in a definitive cure for type 1 diabetes [1-3]. Despite the promises, the only existing, feasible therapeutic alternatives to insulin injections for type 1 diabetic patients are pancreas and islet allo-transplantations from deceased or living organ donors [4-7]. Encouraging achievements in the field of pancreas and islet transplantation, at least in a selected cohort of adult type 1 diabetic patients, have been obtained in recent years [8-10]. 
Table 1 Donor features and isolation outcome

\begin{tabular}{|c|c|c|c|c|c|c|c|c|c|c|c|}
\hline \multicolumn{5}{|c|}{ Donor characteristics } & \multicolumn{2}{|c|}{$\begin{array}{l}\text { Pancreas digestion } \\
\text { parameters }\end{array}$} & \multicolumn{5}{|l|}{ Yield } \\
\hline \multirow[b]{2}{*}{$\begin{array}{l}\text { Donor } \\
\text { pancreas }\end{array}$} & \multirow[b]{2}{*}{$\begin{array}{l}\text { Age } \\
\text { (years) }\end{array}$} & \multirow[b]{2}{*}{ Sex } & \multirow[b]{2}{*}{$\begin{array}{l}\text { Cold } \\
\text { ischaemia } \\
\text { time }(\mathrm{h})\end{array}$} & \multirow[b]{2}{*}{$\begin{array}{l}\text { BMI } \\
\left(\mathrm{kg} / \mathrm{m}^{2}\right)\end{array}$} & \multirow[b]{2}{*}{$\begin{array}{l}\text { Pancreas } \\
\text { weight } \\
\text { (g) }\end{array}$} & \multirow[b]{2}{*}{$\begin{array}{l}\text { Time in } \\
\text { Ricordi } \\
\text { chamber } \\
\text { (min) }\end{array}$} & \multicolumn{3}{|c|}{ Weighted average multiple fractions } & \multicolumn{2}{|c|}{ Purest fraction } \\
\hline & & & & & & & IEQ & $\begin{array}{l}\text { Percent of } \\
\text { purity (islets/ } \\
\text { whole } \\
\text { tissue) }\end{array}$ & $\mathrm{IEQ} / \mathrm{g}$ & IEQ & $\begin{array}{l}\text { Percent of } \\
\text { purity (islets/ } \\
\text { whole } \\
\text { tissue) }\end{array}$ \\
\hline 1 & 6 & $\mathrm{~F}$ & 19 & 15.3 & 30 & 54 & 115,033 & 58 & 4,108 & 78,183 & 67 \\
\hline 2 & 14 & M & 12 & 24.8 & 40 & 75 & 309,100 & 74 & 7,728 & 54,500 & 90 \\
\hline 3 & 5 & $\mathrm{~F}$ & 9 & 14.6 & 16.7 & 77 & 15,062 & 45 & 901 & - & _ \\
\hline 4 & 13 & $\mathrm{~F}$ & 13 & 23.6 & 47.5 & 90 & 354,000 & 73 & 7,453 & 203,000 & 82 \\
\hline 5 & 6 months & $\mathrm{F}$ & 6 & 15 & 11.7 & 68 & 145,500 & 67 & 12,436 & 68,000 & 75 \\
\hline 6 & 4 & $\mathrm{~F}$ & 4.5 & 15.9 & 39.1 & 99 & 145,250 & 60 & 3,714 & 145,250 & 60 \\
\hline 7 & 13 & $\mathrm{~F}$ & 8 & 23.0 & 30.3 & 69 & 314,600 & 49 & 10,382 & 84,600 & 75 \\
\hline 8 & 5 & M & 11.5 & 12.4 & 41.3 & 88 & 48,899 & 58 & 1,183 & - & $\ldots$ \\
\hline 9 & 15 & M & 13 & 21.8 & 92.4 & 104 & 200,000 & 35 & 2,167 & - & - \\
\hline 10 & 13 & M & 12 & 25 & 61.2 & 85 & 188,000 & 67 & 3,071 & 88,000 & $\overline{7} 5$ \\
\hline 11 & 2 & M & 7 & 20.1 & 10.2 & 80 & 56,138 & 42 & 5,503 & - & _ \\
\hline 12 & 5 & $\mathrm{~F}$ & 5 & 19.3 & 41.6 & 107 & 189,603 & 56 & 4,557 & 58,891 & $\overline{70}$ \\
\hline 13 & 17 & $\mathrm{~F}$ & 8 & 23.3 & 36.7 & 74 & 367,000 & 78 & 10,000 & 117,000 & 85 \\
\hline 14 & 17 & M & 7 & 20.6 & 76.3 & 77 & 373,000 & 57 & 4,889 & 264,000 & 60 \\
\hline 15 & 16 & $\mathrm{~F}$ & 4.5 & 16.4 & 60.1 & 75 & 281,033 & 62 & 4,675 & 75,150 & 95 \\
\hline
\end{tabular}

However, progressive improvements together with a broader application of beta cell replacement therapies will certainly raise the problem of availability of good quality donor tissues. Despite continuous efforts to make more human donors accessible for transplantation purposes, the selection, logistics and allocation of deceased donor tissue are not optimised to meet the growing demand [11]. According to UNOS (United Network for Organ Sharing) approximately 2,000 pancreases from deceased organ donors were available in the USA in $2004,20 \%$ of which were from patients younger than 18 years of age. ${ }^{1}$ However, only a limited number of pancreatic organs from young donors are utilised for pancreas or islet cell transplantation [12].

Considering islets, one of the major obstacles to the utilisation of young donor pancreases is the technical inability to obtain a highly purified isolated islet product suitable for islet transplantation [13-16]. More specifically, islets of young human donor pancreases are surrounded,

\footnotetext{
${ }^{1} 2005$ Annual Report of the US Organ Procurement and Transplantation Network and the Scientific Registry of Transplant Recipients: Transplant Data 1995-2004. Department of Health and Human Services, Health Resources and Services Administration, Healthcare Systems Bureau, Division of Transplantation, Rockville, MD; United Network for Organ Sharing, Richmond, Virginia; University Renal Research and Education Association, Ann Arbor, Michigan.
}

even after isolation and purification, by layers of exocrine cells (mantled islets) [13]. If, on the one hand, the surrounding mantle of acinar cells may confer mechanical protection to the islet, on the other, the exocrine layer forms a barrier that prevents an adequate diffusion of nutrients and impairs the ability of islets to interact with the surrounding microenvironment. From a qualitative point of view, however, the pancreatic cells of younger donors would represent a very precious cell source for transplantation. In contrast with what is observed in pigs [17, 18], human islets are similar in size and morphology in children and in adults. Islets from young deceased donors exhibit high qualitative features demonstrated by their ability to efficiently correct diabetes in mouse models, as also shown in our study. Their good islet graft performance is, most likely, a consequence of the optimal donor characteristics. The medical history of younger donors is usually uneventful and the incidence of chronic pathological conditions is extremely low, having, with the exception of type 1 diabetes, little or no effect on the functional status of the islets. Previous studies in rodent models have established an inverse correlation between duration of islet graft function and donor age [19]. In clinical transplantation, pancreases obtained from young donors showed good performance in adult recipients [20], providing an additional rationale to justify the efforts to improve the isolation of islets from young donors and overcome the technical limitations in their complete purifica- 

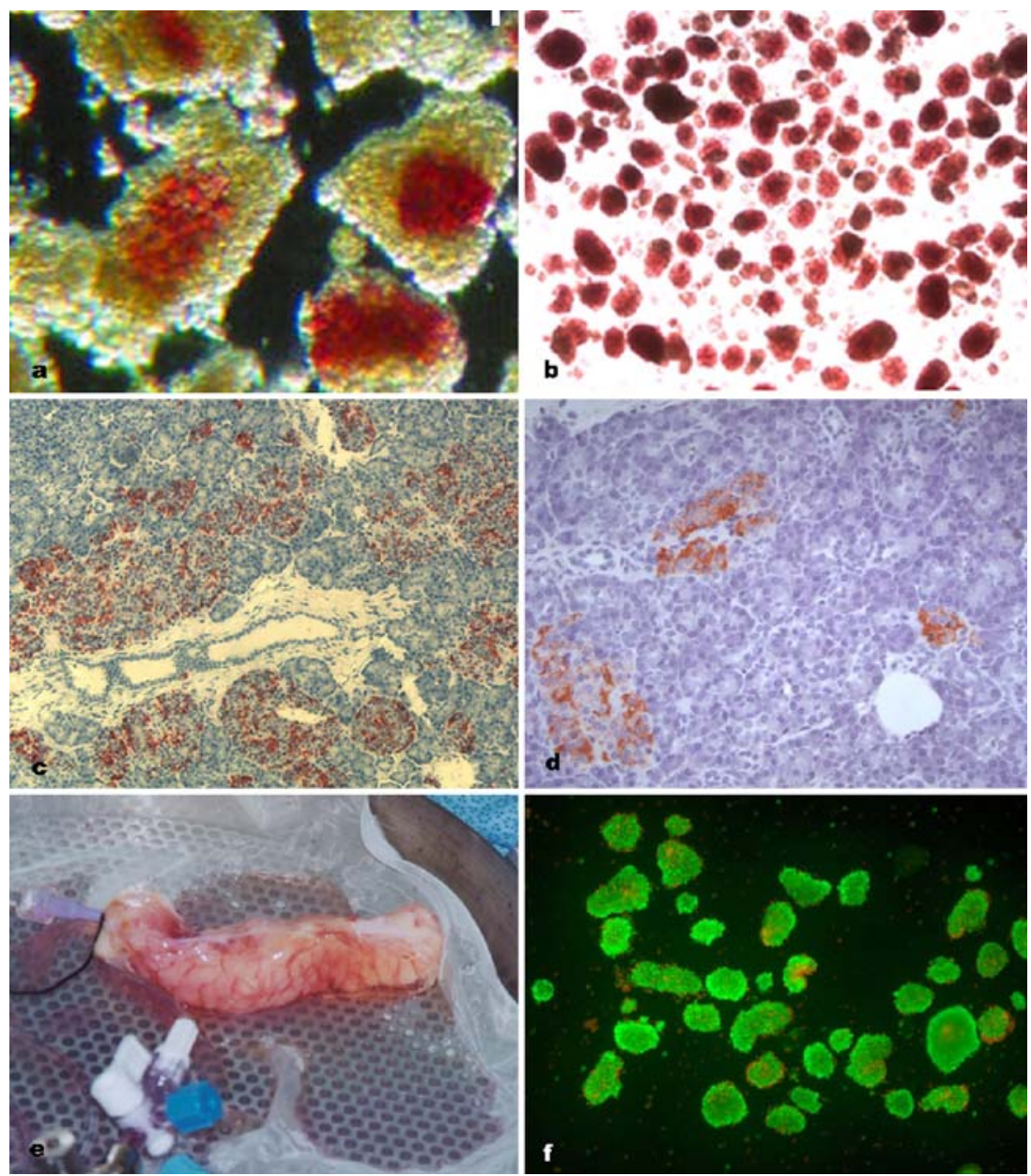

Fig. 1 a Typical example of mantled islets as commonly obtained from young donors. The islets are surrounded by layers of acinar cells. The crimson red staining (dithizone staining) indicates the islets. Magnification $\times 20$. b Islets from a 5 -year-old donor isolated with our modified technique. The islets, stained with dithizone, are mantle-free. Magnification $\times 4$. c Immunocytochemistry staining of a 2-year-old donor pancreas before islet isolation. Red stain indicates immunoreactive insulin-positive cells. The islets are fully formed. Magnification $\times 20$. d Insulin immunostaining of a 50-year-old donor pancreas before isolation for morphological comparison. Magnification $\times 20$. e Image of a 6-month-old pancreatic organ during perfusion in the Rajotte recirculator. Cannulation of the pancreatic duct - for enzyme solution infusion - is carried out at the duodenal end of the duct. f Fluorescent image of islet viability in young donor (5-year-old) islets 3 days after isolation. Green (viable) and red (dead) fluorescence highlights uptake of calcein-AM or propidium iodide, respectively. Magnification $\times 4$ tion. Very few reports have addressed the use of paediatric donors for islet isolation $[15,16]$.

We have standardised a new procedure that allows extraction of purified and mantle-free islets from donors younger than 18 years of age. Although mantled islets are frequently obtained also from young adult donors, in donors 18 years old and younger, mantled islets are virtually always present. The technique of isolation, based on the standard approach used for adult islet isolation, involves crucial procedural modifications aimed at suiting the peculiar structure of the pancreatic organs of young donors. Our islets performed well in vitro and were qualitatively superior to islets of older donors in experiments carried out in vivo.

\section{Subjects and methods}

Modified islet isolation procedure suitable for young donors Fifteen young ( 6 months to 17 years old) donor pancreases, unsuitable for whole pancreas transplantation, were obtained from CORE (Center for Organ Recovery and Education, Pittsburgh, PA, USA, $n=13$ ) and NDRI (National Disease Research Interchange, Philadelphia, PA, USA, $n=2$ ) with permission. Organs were harvested according to standard procedures and transported to the isolation facility in University of Wisconsin or histidinetryptophan-ketoglutarate solutions. Donor characteristics are summarised in Table 1. 
The islet isolation approach described in this study is based on the observation that young donors usually yield islets surrounded by layers of exocrine tissue, forming the so-called 'mantled islets' (Fig. 1a) [13]. In order to reduce the thickness or completely eliminate the surrounding acinar tissue attached to the islets, we have implemented some modifications to the standard isolation procedure commonly used for adult pancreatic organs.

The principle of the method here proposed is to allow a more efficient enzymatic digestion, reducing the mechanical disruption of the pancreas. Our approach involves the following steps: delivery of enzyme solution and initial digestion using the recirculation chamber designed by $\mathrm{R}$. Rajotte [21], further digestion in a Ricordi chamber equipped with additional filtration devices, minimisation of mechanical shaking, and collection of islets through a tissue sieve filter. A collection phase with warm and cold recirculation was also followed in some isolations, as described previously [22].

The pancreas is cleaned from surrounding fat and connective tissue and the pancreatic duct is cannulated (average manipulation time $35.6 \mathrm{~min}$, ranging between 19 and $60 \mathrm{~min}$ ). In organs with a weight lower than $50 \mathrm{~g}$, enzyme perfusion and inflation was achieved by cannulation of one end of the main duct (duodenal end). Larger pancreases required, similarly to adult organs, sectioning of the pancreas body and double duct cannulation (of pancreatic head and body, respectively). The size of the catheter used ranged between 20 and $24 \mathrm{G}$, reflective of the small diameter of the duct. Liberase-HI (Roche, Indianapolis, IN, USA) or collagenase-P (Roche) from multiple lots was used. Liberase-HI $(n=4$, isolation numbers $1,2,5$ and 13 at a concentration of $1.4-2 \mathrm{mg} / \mathrm{ml}$ ) or collagenase-P $(n=11,1.0-1.7 \mathrm{mg} / \mathrm{ml})$ in HBSS solution, pre-warmed to $30^{\circ} \mathrm{C}$, was continuously infused in the duct using the Rajotte recirculation apparatus [21]; however, in the first five isolations we used the syringe injection technique (manual injection with a 60-ml syringe). Enzyme infusion and recirculation was maintained for approximately $17 \mathrm{~min}$ (range 14-22 $\mathrm{min}$ ), regardless of the infusion method used. After enzyme delivery, recirculation was discontinued and the inflated pancreas was maintained for approximately $10 \mathrm{~min}$ in a stationary incubation step devoid of any manipulation. The pancreas was then cleaned of the capsule and residual fat, and then placed in the Ricordi chamber [23]. Two $430-\mu \mathrm{m}$ meshes (in place of one) were inserted in the Ricordi chamber to ensure a better filtration of the circulating cell clusters. An additional filtration system (tissue sieve wire mesh, $500-\mu \mathrm{m}$ diameter) was placed in a collection beaker to further prevent the release of large-size cell clusters in the circulation.

Digested pancreatic aggregates were subsequently purified in a COBE 2991 cell separator (Gambro, Lakewood,
CO, USA) using discontinuous Euro-Ficoll gradients [24]. Isolated islets were cultured in CMRL-1066 medium (Cellgro Mediatech, Herndon, VA, USA) supplemented with additives, as described [25]. Islet count (expressed as islet equivalent number, IEQ), and purity (islets/whole tissue) were determined after dithizone staining (Sigma, St Louis, MO, USA) [26].

Morphological and histological studies The histo-anatomical structure of pancreatic islets (from the whole pancreas prior to isolation and from the islet samples after isolation) was assessed in formalin-fixed tissue/cells after haematoxylin and eosin (H\&E) staining as well as insulin immunostaining (DakoCytomation, CA, USA), as described [22]. Islet size measurement was performed using an Axiplan 2ie MOT Research Microscope (Carl Zeiss Micro imaging, NY, USA).

Insulin secretory characteristics and islet viability Islet insulin secretory ability was assessed in vitro by static or dynamic exposure to Krebs Ringer bicarbonate buffer containing low $(2.8 \mathrm{mmol} / \mathrm{l})$ and high $(20 \mathrm{mmol} / \mathrm{l})$ glucose $[24,27]$.

For basal, unstimulated, insulin release during culture, groups of 50 handpicked islets (diameter of each islet between 150 and $250 \mu \mathrm{m}$ ) were re-suspended in $2 \mathrm{ml}$ of fresh medium and maintained under standard culture conditions in an incubator for $60 \mathrm{~h} \mathrm{[25].} \mathrm{Insulin} \mathrm{concentra-}$ tion in the culture medium, or after islet insulin extraction, was measured by ELISA (ALPCO, Windham, NH, USA) $[22,24]$. DNA content of islets was determined as described [24]. Islet cell viability was determined using a double fluorescence (calcein AM and propidium iodide) membrane-integrity assay [28].

In vivo transplantation Following a minimal overnight culture, islet grafts composed of a marginal mass of 150350 (adjustment in number reflects difference in islet size) handpicked islets were transplanted under the renal capsule of diabetes-induced NOD-scid mice (Jackson Laboratories, Bar Harbor, ME, USA), as described [29, 30]. Islet graft preparations were obtained from ten different donors younger than 18 years (study group) and implanted in 32 mice. Diabetes was induced in the mouse recipients, prior to transplantation, by single i.p. administration of streptozotocin $(230 \mathrm{mg} / \mathrm{kg}$ body weight; Sigma) [29, 30]. All procedures were carried out in accordance with the guidelines of the Institutional Animal Research Care Committee of the University of Pittsburgh. Glycaemic levels of recipients were recorded periodically for over 1 month following transplantation. Two consecutive glycaemic levels $<200 \mathrm{mg} / \mathrm{dl}$ indicated normalisation of the recipients. The kidneys bearing grafts were removed at least 1 month 

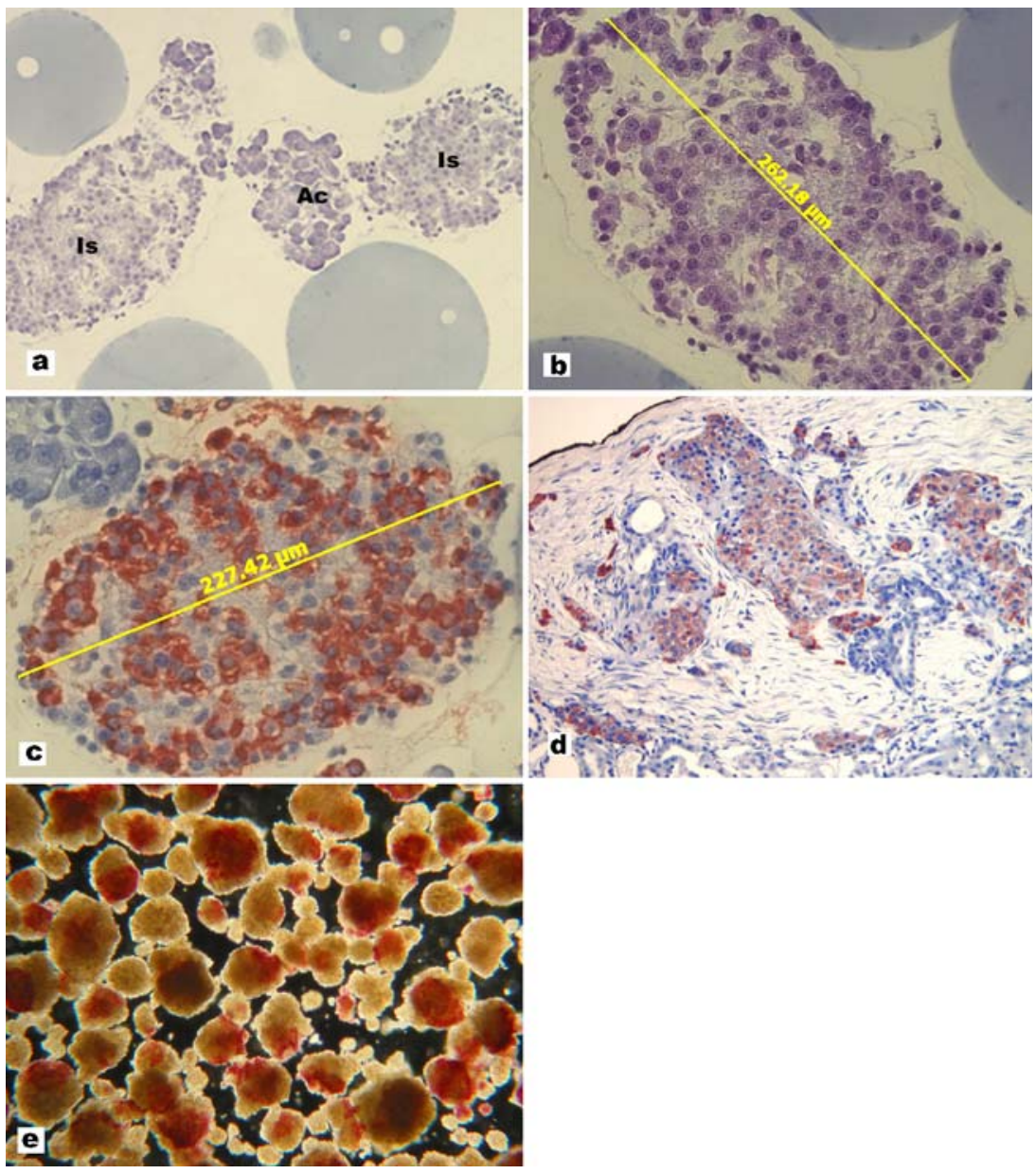

Fig. 2 a H\&E staining of young donor islets after isolation. Morphology reflects exocrine mantle-free status of the islets. Is, islet; $A c$, acinar cells. Magnification $\times 20$. b H\&E-stained islet from a 5year-old donor shows mantle-free status. Size is indicated. Magnification $\times 60$. $\mathbf{c}$ Red insulin immunostaining of an isolated islet from a 13 -year-old donor shows absence of surrounding exocrine layers. Size is indicated. Magnification $\times 60$. d Young donor (13-year-old) islet graft under the renal capsule of a mouse recipient 46 days after transplantation. Magnification $\times 20$. e Mantled islets from a young adult donor, obtained using the standard, unmodified isolation procedure. Magnification $\times 4$ after the transplantation and return to hyperglycaemia was interpreted as indirect evidence of the ability of the graft to maintain normoglycaemia in the recipient. The removed islet grafts were immunostained with anti-insulin antibodies.

For comparison, in vivo transplantation data, where islet grafts with similar marginal mass were obtained from 21 donors between 18 and 50 years old, and 36 donors of 50 years of age and older, were considered.

Statistical analysis The trend in proportion of successful in vivo transplantation outcome across different organ donor age groups $(<18,18-50$ and $>50$ years $)$ was tested using the Cochran-Armitage $\chi^{2}$ test and the effect size odds ratio was calculated using a logistic regression model.

Pearson's correlation coefficient and linear regression analysis was used to test the relationship between islet yield and other continuous covariates. Analyses were performed using SAS software version 9.

\section{Results}

Morphological characteristics An image of a pancreas section prior to isolation stained for immunoreactive insulin, showing intact, fully formed islets in a young donor is shown in Fig. 1c. Islet size and morphology are compared with the adult pancreas (Fig. 1d). Also shown are isolated islets of Langerhans stained with dithizone (Fig. 1b), H\&E (Fig. 2a,b) and anti-insulin antibodies (Fig. 2c). Insulin staining highlights the islet beta cells. The islets are devoid of the exocrine mantle. 


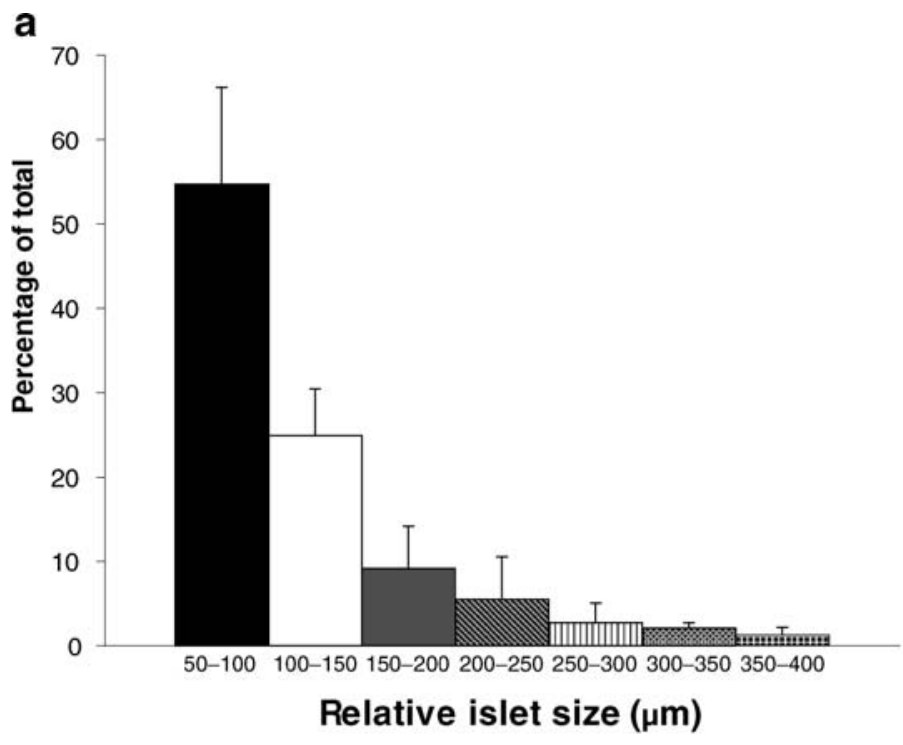

C

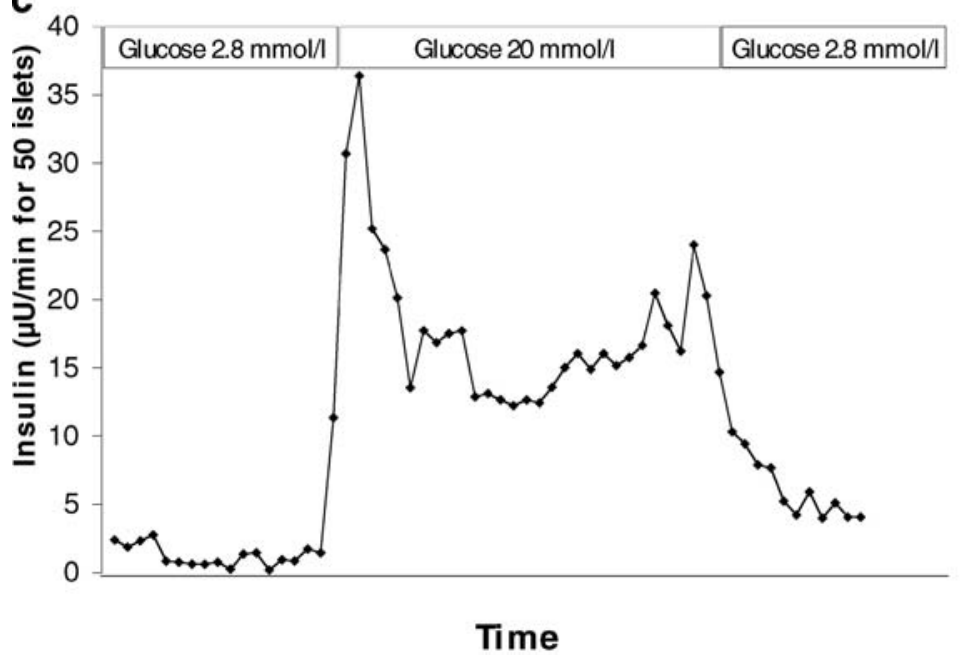

b

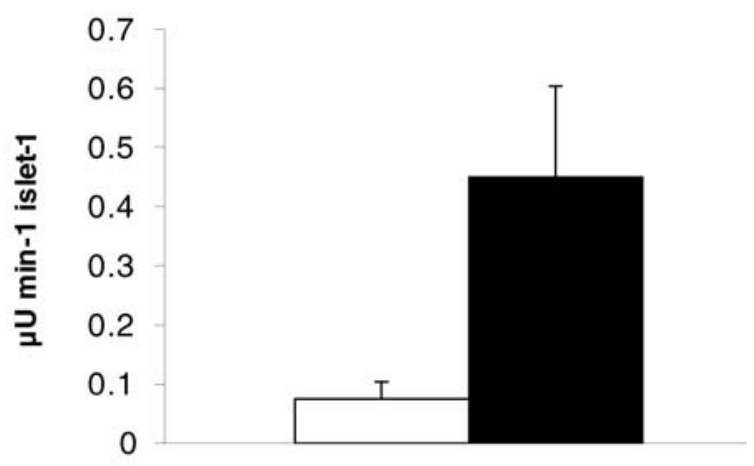

d

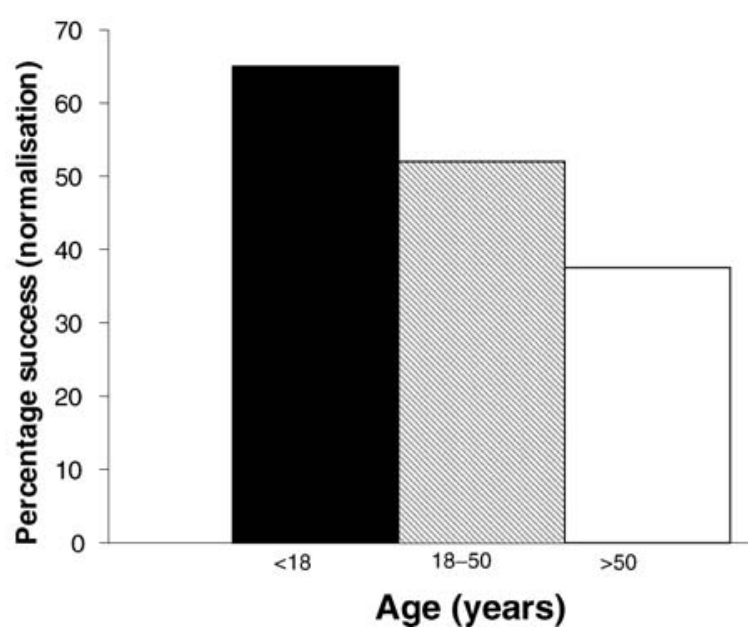

Fig. 3 a Islet size from young donors after isolation $(n=10)$. b Insulin secretion after glucose challenge in vitro. Bars represent insulin amounts released after low $(2.8 \mathrm{mmol} / \mathrm{l}$, empty bar $)$ and high $(20 \mathrm{mmol} / \mathrm{l}$, filled bar) glucose stimulation in isolated young donor islets. Data are means $\pm \mathrm{SEM}$ of ten islet donor preparations. c Representative dynamic perifusion curve of islets from a 6-month-old donor. d In vivo transplantation success rate according to donor age. The $\chi^{2}$ test showed a significant trend in proportions across all age groups $\left(\chi^{2}=8.67,1\right.$ $d f, p=0.0032$ ). Age group $<18$ years, $n=32$; age group $18-50$ years, $n=54$; age group $>50$ years, $n=104$

digestion, at the cost of a reduced mechanical digestion, without increasing the overall total time of exposure of the pancreatic tissue to exogenous enzymes which are potentially harmful [22, 27]. In order to inject the enzyme solution, typically, in adult organs, the pancreatic neck is cut to expose the two-sectioned parts of the gland as well as the pancreatic duct. Two catheters are inserted into the two halves of the sectioned pancreatic duct: one towards the head and the second towards the body-tail. However, in young donor organs not exceeding $50 \mathrm{~g}$ in weight, the duct was cannulated at the level of the head with only one cannula (Fig. 1e). The advantage of this approach is to reduce the area around the cut that is usually poorly distended and consequently under-digested. Delivery of 
exogenous enzyme solution, pre-warmed to $30^{\circ} \mathrm{C}$, was carried out very slowly and was maintained for 14-22 min to initiate the digestion already at this stage. As described in detail in Subjects and methods, the Ricordi chamber was equipped with two metallic meshes of $430 \mu \mathrm{m}$ diameter each to efficiently regulate the flow of cell aggregates during the recirculation. The double mesh served the purpose of preventing the recirculation of large size aggregates. On average, the pancreas was maintained in the digestion chamber for $1 \mathrm{~h}$ and $21 \mathrm{~min}$ (inclusive of digestion and collection phases), ranging between $54 \mathrm{~min}$ and $1 \mathrm{~h}$ and $47 \mathrm{~min}$. Shaking of the chamber was extremely gentle for the entire procedure to avoid mechanical islet release. Free islets appeared at variable periods of time after the organ was placed in the Ricordi chamber, between 5 and 15 min after the intra-chamber temperature reached $37^{\circ} \mathrm{C}$, and collection of the isolated islets was initiated when the majority of islets were free of surrounding acinar cells. In seven of the preparations, collection of the cell aggregates was carried out in warm and subsequently cold medium, as described previously [22], while the other eight preparations were collected directly in cold medium.

Pancreas weight and digestion parameters of the 15 isolations are shown in Table 1. For those seven pancreatic preparations diluted with warm medium, the average warm collection lasted $17 \mathrm{~min}$, with times ranging between 11 and $21 \mathrm{~min}$. The average length of cold collection was $40 \mathrm{~min}$, ranging between 24 and $58 \mathrm{~min}$. Digestion time (time-course starting when the internal temperature in the digestion chamber is $37^{\circ} \mathrm{C}$ and the beginning of cold recirculation) was $30 \mathrm{~min}$, on average, ranging between 14 and $44 \mathrm{~min}$. After digestion, in 11 of the 15 preparations some undigested pancreatic tissue was found, mostly in negligible amounts ( $<5 \%$ initial weight) except for one case where $\sim 30 \%$ of the pancreas (mainly the pancreatic head) was not fully processed. Purification was then carried out using discontinuous gradients as described and the final islet yield is shown in Table 1 . We found a positive correlation between yield (IEQ) and BMI. The correlation between the islet yield (in thousands) and donor age was $0.83(p \leq 0.001)$, and for islet yield and BMI it was 0.69 $(p=0.005)$. The linear regression analysis showed an average expected $19.80\left(\times 10^{3} \mathrm{IEQ} /\right.$ pancreas $)$ increase in islet yield for an average $1 \mathrm{~kg} / \mathrm{m}^{2}$ increase in BMI and this was statistically significant $(r=0.47, p=0.005)$. A positive correlation was also observed between donor age and pancreas weight $(r=0.71, p=0.003)$, age and BMI $(r=0.66$, $p=0.008)$. The majority of the isolation procedures yielded two islet-enriched fractions with different purity (islet content/whole tissue). Data expressed as weighted average of multiple fractions indicate the overall islet number and purity adjusted to represent the relative contribution of each fraction with different purity. Islet yield and purity related to the most pure fraction for each donor preparation are also shown. Purest fractions averaged $74 \%$ of islets/whole tissue, and were almost completely devoid of mantled islets, while the less pure were between 35 and 60\% (data not shown) and contained less than $30 \%$ mantled islets. The final islet yield expressed in IEQ included islets with diameters ranging from 50 to $400 \mu \mathrm{m}(n=15)$. Smaller cell aggregates were not counted. The relative proportion for the different islet size groups is reported in Fig. 3a. Islets with a diameter ranging between 50 and $200 \mu \mathrm{m}$ represented almost $90 \%$ of the whole islet preparation, consistent with data accrued on adult islets by our as well as other groups [9, 22].

After successful introduction of our modified method, to further validate its efficacy in a subsequent isolation from a young adult donor, used as control, we reapplied the standard, unmodified procedure and we obtained most exclusively mantled islets, as shown in Fig. 2e.

Islet viability Islet preparations were assayed for viability before in vitro studies as well as prior to transplantation between post-isolation day 2 and 7, using a dual fluorescence approach (as described in Subjects and methods). Viable cells represented 70-90\% (mean \pm SEM $81 \pm 3 \%$, $n=14$ ) of the total (Fig. 1f).

Islet insulin secretory function in vitro Isolated islets were subjected to either static or dynamic glucose challenge to determine islet cell ability to release insulin in response to glucose. Insulin accumulation in the culture medium under basal glucose concentration was also measured after $60 \mathrm{~h}$ of culture. The perifusion results shown in Fig. $3 \mathrm{~b}$ are means \pm SEM of ten islet preparations where unstimulated (lowglucose) insulin release was compared with the average insulin output under high glucose-stimulated conditions. Figure $3 \mathrm{c}$ also shows a representative perifusion curve of dynamic insulin release. Stimulation index, expressed as mean basal over mean stimulated insulin release, was $7.2 \pm 2$ (mean \pm SEM, $n=10$ ).

Basal insulin accumulation over a 60 -h culture period under standard conditions was on average 5,257 $\pm 1,010 \mu \mathrm{U} /$ $\mathrm{ml}$ for 50 islets, which is comparable with insulin release of adult pancreatic islets $(4,671 \pm 1,282 \mu \mathrm{U} / \mathrm{ml}$ for 50 islets $)$ [22] maintained in the same culture conditions. Insulin content for islets of diameter of 150-250 $\mu \mathrm{m}$ diameter was $650 \pm 107 \mu \mathrm{U} /$ islet and DNA content $27 \pm 4 \mathrm{ng} /$ islet (mean \pm SEM, $n=3-7$ donor preparations). These values are also similar to adult islets [31].

In vivo transplantation Routine quality control assays of isolated islets include transplantation of a marginal mass (150-350 handpicked islets, due to differences in islet size) under the kidney capsule of immunodeficient (NOD-scid) 
mice made diabetic by administration of streptozotocin. The choice of a limited islet mass allows for more stringent qualitative assessment of the islet preparation. With a marginal mass, approximately half of the recipients achieve normalisation, thus reflecting more accurately the qualitative status of the islets. We looked at the normalisation rate of diabetic animals receiving islet grafts from young donors (age $<18$ years) compared with two older donor age groups (18-50 years) and $>50$ years performed in our laboratory (Fig. 3d). All mice received islet grafts composed of 150 350 handpicked islets, on average $219 \pm 13,232 \pm 8$ and $218 \pm$ 6 (means \pm SEM, difference not statistically significant) for donor age groups $<18,18-50$ and $>50$ years, respectively. Outcome in recipients of juvenile pancreatic islets (donor age $0-18$ years) was $65 \%$, compared with $54 \%$ for adult donors (age 18-50 years) and only 37.5\% for older donor islets.

The $\chi^{2}$-test showed a significant trend in proportions across all age groups $\left(\chi^{2}=8.67,1 d f, p=0.0032\right)$ with more percentage success in younger age groups. The estimated odds of successful transplantation outcome is 3.18 times (95\% CI 1.38-7.30, $p=0.0063)$ more when donor age is 0 18 years compared with donor age $>50$. An elevated odds of successful transplantation was observed in donors whose age was between 18 and 50 compared with those whose age was 50 and above (1.80 [95\% CI 0.92-3.49, $p=0.0848]$ ) and is significant at the $8 \%$ level of significance. Similarly, a 1.77-fold increase (95\% CI $0.72-4.38, p=0.2145$; not significant) in the odds of successful transplantation was observed in 0 - to 18-year-old donors compared with 18- to 50 -year-old donors. These data strongly indicate that islets isolated from younger donors survived better and performed more efficiently. Removal of the kidney capsule with the islet graft resulted in return to hyperglycaemia in all recipients, whenever performed. Figure $2 \mathrm{~d}$ shows insulin-positive cells from a young donor under the kidney capsule of a mouse recipient, 46 days after transplantation.

\section{Discussion}

The ability of isolated islet cells to correct hyperglycaemia following transplantation in diabetic patients is strongly affected by factors related to quality and size of the islet mass implanted. In order to restore normoglycaemia, a large islet mass, usually pooled from multiples donors, is required. Only in selected cases was islet transplantation outcome successful as a result of single donor islet infusion [32], and due to the adoption of an inversed BMI between donors and recipients [33].

It is known that overweight adult islet donors are favoured as they provide consistently large numbers of puri- fied islets. Deceased donors younger than 18 years of age, representing approximately $20 \%$ of the total pool of organ donors $^{2}$, have been, on the contrary, minimally utilised for pancreas and islet transplantation.

One of the arguments is the general assumption that young pancreases contain a lower islet mass. There is no clear-cut evidence of strong differences in beta cell content according to age; however, in our study we could observe a positive correlation between donor age, pancreas size, BMI and islet yield, with higher islet numbers obtained from the pancreases of adolescents than from young children. Beside the overall yield, no qualitative difference was noticed either in vitro or in vivo, according to age. Histopathological studies on diabetic patients, as well as evidence accrued from patients undergoing partial excision of the pancreas, suggest even a reduced islet mass maintains long-term glucose metabolism, and the outcome of paediatric pancreas transplantations also confirms that a juvenile pancreatic islet mass is sufficient to sustain the metabolic demands of adult, immunosuppressed, diabetic patients [20]. In our study, we showed that, from a morphological and in vitro functional point of view, young donor islets are similar to adult ones. We also demonstrated that juvenile islets show significantly superior ability to normalise diabetic recipient mice following transplantation of a marginal mass compared with older donors. Such higher ability, not fully paralleled by better functional parameters in vitro, suggests that younger islets may have higher resistance to the stressful events that characterise the transplantation setting, and subsequent engraftment, with important implications for clinical application.

The problem encountered in isolating islets from juvenile pancreatic organs is mostly technical. Using the traditional method designed for adult human pancreatic islet isolation, islets in young donors are usually difficult to separate from the surrounding exocrine cells. Not only are islets mantled, therefore completely surrounded by exocrine cells, but the numbers of exocrine cells that surround the islets are so large that the size of each aggregate may raise problems in view of the intravascular infusion in clinical transplantation. Diffusion of nutrients in larger islet aggregates both in culture and after transplantation is far from ideal, affecting cell survival and exocrine contamination of the islet preparation, and contributes to impairment of islet engraftment [34, 35]. Possible reasons for an inefficient separation of the islets from the neighbouring tissues are consistent with anatomical and physiological aspects. Investigators reported that, in younger human pancreases, the ducts are collapsed towards the islet cells, therefore infusion of exogenous enzyme solution via the pancreatic ductal system may fail to distribute properly

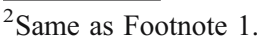


throughout the parenchyma [16]. The more efficient way of delivering the enzyme solution described in this study appears to be instrumental in overcoming these anatomical, age-related features. Of note, removal of the mantle did not appear to jeopardise either islet morphology or survival during culture. Islet loss rate was not different from that of adult islet preparations [24, 27]. Previous work [19] addressed donor age as a factor that affects islet performance; in rodent models of syngeneic and allogeneic islet transplantation it was demonstrated that donor age inversely correlates with the duration of glycaemia normalisation. The potential advantage offered by young donor pancreatic tissue had been addressed already in the 1970s [36]. Subsequently it was reported [37] that pancreatic organs from young donors perform better in human allografts, compared with older and non-heart beating donors [37]. Similar findings were also reported by others [38]. More recent data indicate that the pancreas of a 31-month-old donor was able to establish glycaemia control in an adult recipient, providing superior insulin production ability to sustain a more challenging metabolic requirement [20]. In addition to physiological and metabolic aspects of the islet grafts, younger donors are the focus of studies aimed at identifying and exploiting islet cell precursors as a potential source for beta cell regeneration. The possibility of optimising the isolation of islets from younger donors and thereby increasing the pools of islet donors for clinical use, can be relevant to offering more type 1 diabetes patients beta cell replacement therapy. Our group has developed a method that allows purification of large amounts of islets from young donors with good functional properties.

Acknowledgements The authors are grateful to J. He and C. Knoll for excellent technical assistance. The work was supported in part by grants from the Juvenile Diabetes Research Foundation (JDRF).

Duality of interest statement The authors are not aware of any duality of interest.

\section{References}

1. Trucco M (2005) Regeneration of the pancreatic beta cell. J Clin Invest 115:5-12

2. Rood PP, Bottino R, Balamurugan AN, Fan Y, Cooper DK, Trucco M (2006) Facilitating physiologic self-regeneration: a step beyond islet cell replacement. Pharm Res 23:227-242

3. Bretzel RG, Brendel M, Eckhard M et al (2001) Islet transplantation: present clinical situation and future aspects. Exp Clin Endocrinol Diabetes 109(Suppl 2):S384-S399

4. Shapiro AM, Lakey JR, Ryan EA et al (2000) Islet transplantation in seven patients with type 1 diabetes mellitus using a glucocorticoid-free immunosuppressive regimen. N Engl J Med 343:230-238

5. Fiorina P, Folli F, Zerbini G et al (2003) Islet transplantation is associated with improvement of renal function among uremic patients with type I diabetes mellitus and kidney transplants. J Am Soc Nephrol 14:2150-2158
6. Gray DW (2005) Avoiding damage to transplanted human islets during implantation is important. Transplantation 79:1294-1295

7. Matsumoto S, Okitsu T, Iwanaga $Y$ et al (2005) Insulin independence after living-donor distal pancreatectomy and islet allotransplantation. Lancet 365:1642-1644

8. Sutherland DE, Gruessner A, Hering BJ (2004) Beta-cell replacement therapy (pancreas and islet transplantation) for treatment of diabetes mellitus: an integrated approach. Endocrinol Metab Clin North Am 33:135-148

9. Korsgren O, Nilsson B, Berne C et al (2005) Current status of clinical islet transplantation. Transplantation 79:1289-1293

10. Ryan EA, Paty BW, Senior PA et al (2005) Five-year follow-up after clinical islet transplantation. Diabetes 54:2060-2069

11. Robertson RP (2004) Islet transplantation as a treatment for diabetes - a work in progress. N Engl J Med 350:694-705

12. Berney T, Buhler LH, Morel P (2005) Pancreas allocation in the era of islet transplantation. Transpl Int 18:763-767

13. Ricordi C (2003) Islet transplantation: a brave new world. Diabetes 52:1595-1603

14. Ricordi C, Alejandro R, Rilo $\mathrm{HH}$ et al (1995) Long-term in vivo function of human mantled islets obtained by incomplete pancreatic dissociation and purification. Transplant Proc 27:3382

15. Ricordi C, Alejandro R, Zeng Y et al (1991) Human islet isolation and purification from pediatric-age donors. Transplant Proc 23:783-784

16. Socci C, Davalli AM, Vignali A et al (1993) A significant increase of islet yield by early injection of collagenase into the pancreatic duct of young donors. Transplantation 55:661-663

17. Dufrane D, Goebbels RM, Fdilat I, Guiot Y, Gianello P (2005) Impact of porcine islet size on cellular structure and engraftment after transplantation: adult versus young pigs. Pancreas 30:138-147

18. Krickhahn M, Buhler C, Meyer T, Thiede A, Ulrichs K (2002) The morphology of islets within the porcine donor pancreas determines the isolation result: successful isolation of pancreatic islets can now be achieved from young market pigs. Cell Transplant 11:827-838

19. Keymeulen B, Anselmo J, Pipeleers D (1997) Length of metabolic normalization after rat islet cell transplantation depends on endocrine cell composition of graft and on donor age. Diabetologia 40:1152-1158

20. Buggenhout A, Hoang AD, Hut F, Lekeufack JB, Bali MA, De Pauw L (2004) Pediatric en bloc dual kidney-pancreas transplantation into an adult recipient: a simplified technique. Benefits of the en bloc kidney-pancreas transplantation technique in pediatric donors. Am J Transplant 4:663-665

21. Lakey JR, Warnock GL, Shapiro AM et al (1999) Intraductal collagenase delivery into the human pancreas using syringe loading or controlled perfusion. Cell Transplant 8:285-292

22. Balamurugan AN, Chang Y, Fung JJ, Trucco M, Bottino R (2003) Flexible management of enzymatic digestion improves human islet isolation outcome from sub-optimal donor pancreata. Am J Transplant 3:1135-1142

23. Ricordi C, Lacy PE, Scharp DW (1989) Automated islet isolation from human pancreas. Diabetes 38 [Suppl 1]:140-142

24. Bottino R, Balamurugan AN, Bertera S, Pietropaolo M, Trucco M, Piganelli JD (2002) Preservation of human islet cell functional mass by anti-oxidative action of a novel SOD mimic compound. Diabetes 51:2561-2567

25. Bottino R, Balamurugan AN, Tse H et al (2004) Response of human islets to isolation stress and the effect of antioxidant treatment. Diabetes 53:2559-2568

26. Latif ZA, Noel J, Alejandro R (1988) A simple method of staining fresh and cultured islets. Transplantation 45:827-830

27. Balamurugan AN, He J, Guo F et al (2005) Harmful delayed effects of exogenous isolation enzymes on isolated human islets: relevance to clinical transplantation. Am J Transplant 5:2671-2681 
28. Lorenzo A, Razzaboni B, Weir GC, Yankner BA (1994) Pancreatic islet cell toxicity of amylin associated with type-2 diabetes mellitus. Nature 368:756-760

29. Bertera S, Crawford ML, Alexander AM et al (2003) Gene transfer of manganese superoxide dismutase extends islet graft function in a mouse model of autoimmune diabetes. Diabetes $52: 387-393$

30. Alexander AM, Crawford M, Bertera S et al (2002) Indoleamine 2,3-dioxygenase expression in transplanted NOD islets prolongs graft survival after adoptive transfer of diabetogenic splenocytes. Diabetes 51:356-365

31. Eizirik DL, Korbutt GS, Hellerstrom C (1992) Prolonged exposure of human pancreatic islets to high glucose concentrations in vitro impairs the beta-cell function. J Clin Invest 90:1263-1268

32. Hering BJ, Kandaswamy R, Ansite JD et al (2005) Single-donor, marginal-dose islet transplantation in patients with type 1 diabetes. JAMA 293:830-835
33. Matsumoto I, Sawada T, Nakano M et al (2004) Improvement in islet yield from obese donors for human islet transplants. Transplantation 78:880-885

34. Gray DW, Sutton R, McShane P, Peters M, Morris PJ (1988) Exocrine contamination impairs implantation of pancreatic islets transplanted beneath the kidney capsule. J Surg Res 45:432-442

35. Heuser M, Wolf B, Vollmar B, Menger MD (2000) Exocrine contamination of isolated islets of Langerhans deteriorates the process of revascularization after free transplantation. Transplantation 69:756-761

36. Sutherland DE, Matas AJ, Steffes MW, Najarian JS (1976) Infant human pancreas. A potential source of islet tissue for transplantation. Diabetes 25:1123-1128

37. Rhein T, Metzner R, Uhlmann D et al (2003) Pediatric donor organs for pancreas transplantation: an underutilized resource? Transplant Proc 35:2145-2146

38. Krieger NR, Odorico JS, Heisey DM et al (2003) Underutilization of pancreas donors. Transplantation 75:1271-1276 